\title{
Intrazeolite Attachment of a Ge-Mo Heterobimetallic Complex
}

\author{
Aticha Borvornwattananont, Karin Moller, and Thomas Bein* \\ Department of Chemistry, University of New Mexico, Albuquerque, NM 87131, U.S.A.
}

$\mathrm{HY}$ zeolite encapsulated $\mathrm{Cl}_{2}$ (thf) GeMo(CO) (thf = tetrahydrofuran), studied by EXAFS, in situ Fourier transform spectroscopy, and temperature programmed desorption (TPD) MS, attaches to the zeolite pore system through the Ge-moiety with retention of the Ge-Mo bond, whereas a large fraction of the intrazeolite $-\mathrm{Mo}(\mathrm{CO})_{5}$ moieties remain unaffected by the anchoring reaction.

The structural and chemical features of zeolites, i.e., crystalline, open pore structures with well-defined co-ordination sites, ion exchange capability, and controlled acidity, make them promising candidates for selective hybrid systems. However, the instability of many zeolite catalyst systems

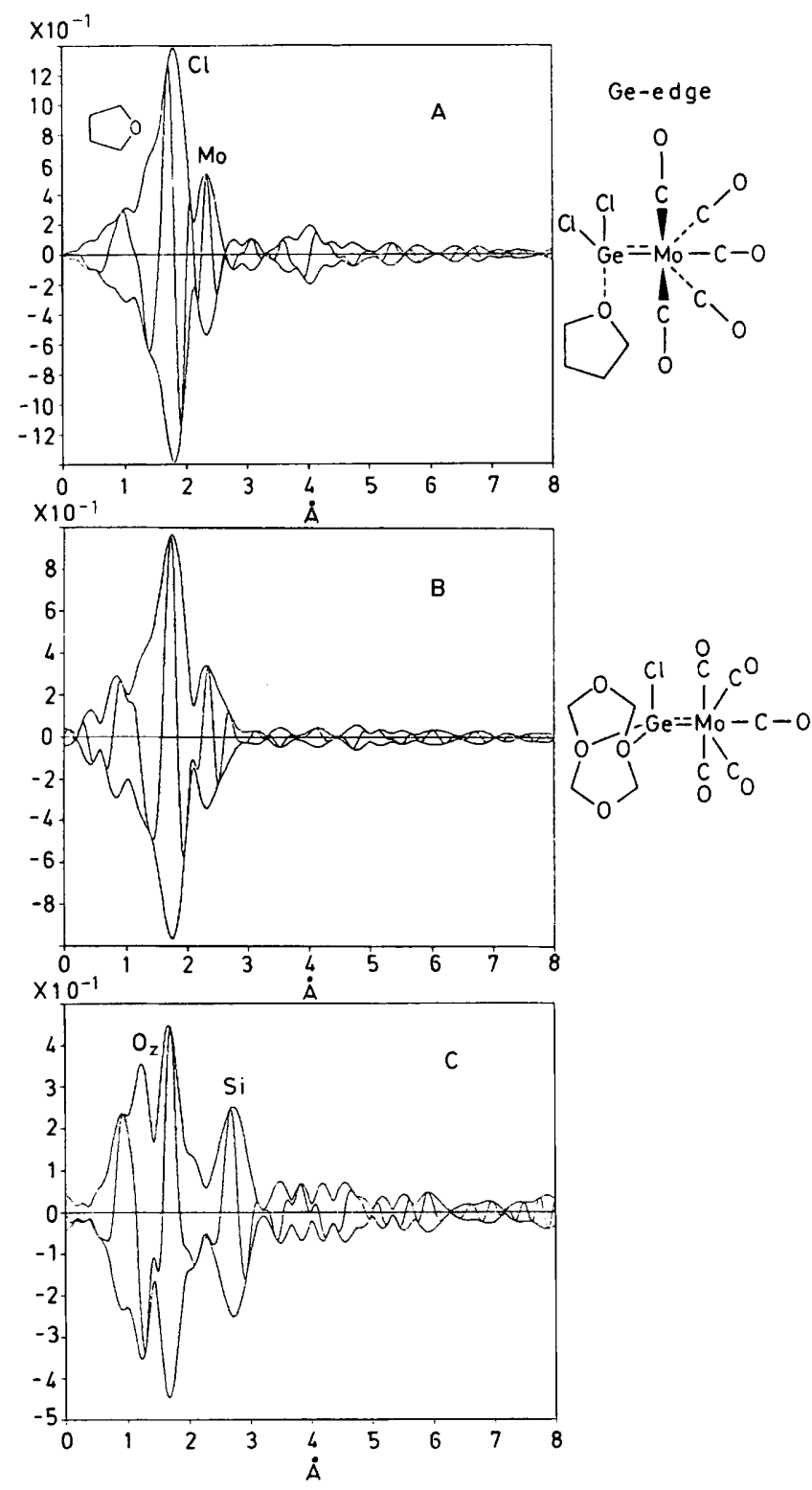

Figure 1. Ge-edge EXAFS data. $k^{2}$-weighted Fourier transformations (FT) of $\mathrm{A}, \mathrm{Cl}_{2}$ (thf) $\mathrm{GeMo}(\mathrm{CO})_{5}$ precursor; $\mathrm{B}, \mathrm{Cl}_{2}$ (thf) $\mathrm{GeMo}(\mathrm{CO})_{5}$ loaded into acid zeolite $\mathrm{HY}$ at room temperature; and $\mathrm{C}$, heated at $520 \mathrm{~K}$. The FTs are uncorrected for phase shifts, thus bond distances appear to be reduced by $0.3-0.5 \AA$. under reaction conditions has been a limiting factor for applications. Different approaches to zeolite-based hybrid catalysts include physisorption of neutral metal carbonyls ${ }^{1}$ (weak binding at metal cations ${ }^{2}$ does not always prevent diffusion and agglomeration), cation-derived species such as Rh-carbonyls, ${ }^{3}$ assembly of diffusionally blocked large complexes such as Co- and Fe-phthalocyanines, ${ }^{4}$ and the use of zeolite hydroxy groups for attaching, e.g., $\mathrm{Rh}(\text { allyl })_{3}{ }^{5}$ or organoiron complexes. 6

We have explored a new approach, introducing heterobinuclear organometallic compounds as candidates for linking catalytic functions to zeolite frameworks. With two different metals present, the complexes can be anchored to the support via one oxophilic metal, whereas catalytic reactions may proceed at the second metal centre.

Zeolite HY, derived from Linde LZ-Y62 $\left[\left(\mathrm{NH}_{4}\right)_{45^{-}}\right.$ $\mathrm{Na}_{10} \mathrm{Al}_{55} \mathrm{Si}_{137} \mathrm{O}_{384}$ ] by degassing at $700 \mathrm{~K}$ for $10 \mathrm{~h}\left(1 \mathrm{~K} \mathrm{~min}^{-1}\right)$, was used as a support. A slurry of $0.500 \mathrm{~g}$ of the zeolite in $50 \mathrm{ml}$ of pentane was loaded, stirring under nitrogen for $12 \mathrm{~h}$ with 1 molecule of $\mathrm{Cl}_{2}$ (thf) $\mathrm{GeMo}(\mathrm{CO})_{5}(1)$ (thf = tetrahydrofuran) per supercage, prepared from $\mathrm{Na}_{2}\left[\mathrm{Mo}_{2}(\mathrm{CO})_{10}\right]$ and $\mathrm{GeCl}_{4}$ in THF at $120 \mathrm{~K} .{ }^{7}$ The solvent was removed by filtration on a frit. EXAFS data at the $\mathrm{Ge} K$-edge $(11103 \mathrm{eV})$ and the Mo $K$-edge $(20000 \mathrm{eV})$ of sealed samples at $100 \mathrm{~K}$ were obtained at NSLS (Brookhaven National Laboratories) at beamline X-11A. The EXAFS data were analysed using structural parameters taken from appropriate reference compounds.

The EXAFS data of the precursor $\mathrm{Cl}_{2}$ (thf) $\mathrm{GeMo}(\mathrm{CO})_{5}(\mathbf{1})$ (no crystal structure has been published) show, at the $\mathrm{Ge}$ edge, the expected co-ordination to thf $\left(\mathrm{Ge}-\mathrm{O}_{1.1}\right.$ at $\left.2.06 \AA\right)$, to $\mathrm{Cl}\left(\mathrm{Ge}-\mathrm{Cl}_{2.0}\right.$ at $\left.2.15 \AA\right)$, and the $\mathrm{Ge}-\mathrm{Mo}$ bond at $2.64 \AA$ (Figure 1A). The corresponding Mo-edge data reveal $\mathrm{Mo}-\mathrm{CO}$ at 2.05, Mo-CO at 3.18, and Mo-Ge co-ordination at $2.68 \AA$.

If (1) is diffused into the acid zeolite host at $295 \mathrm{~K}$ [HY/(1)], no substantial changes in the FTIR spectrum of the precursor are observed, indicating the presence of intact $-\mathrm{Mo}(\mathrm{CO})_{5}$ moieties in the zeolite. We note that the strong $\mathrm{CO}$-stretch of (1) in a NaY host shifts to lower frequency, probably due to $\mathrm{Na}^{+}-\mathrm{OC}$ - interactions similar to those of nickel carbonyl complexes in NaY. ${ }^{2}$ The Ge-edge EXAFS data of $\mathrm{HY} /(\mathbf{1})$ (Figure 1B) show reduced co-ordination to $\mathrm{Cl}\left(\mathrm{Ge}-\mathrm{Cl}_{1.3}\right.$ at $2.20 \AA$ ) and increased co-ordination to oxygen at a longer distance $\left(\mathrm{Ge}-\mathrm{O}_{1.8}\right.$ at $2.13 \AA$ ) which indicates that the complex (1) has attached to the zeolite framework oxygen atoms, according to equation (1).

$\mathrm{Cl}_{2}$ (thf)GeMo(CO $)_{5}+\mathrm{HOZ}, \mathrm{OZ} \rightarrow(\mathrm{ZO})_{2}-\mathrm{ClGeMo}(\mathrm{CO})_{5}$
$+\mathrm{HCl}$

The corresponding Mo-edge data of $\mathrm{HY} /(\mathbf{1})$ show a moderate reduction of the average Mo-carbonyl co-ordination number from 5 to 3 , indicating that even the highly acidic environment of the HY host attacks only a minor fraction of the precursor (1). A distinct Ge-Mo interaction at $2.70 \AA$ (Geand Mo-edges, co-ordination numbers $c a .1$ ) shows that the binuclear complex is maintained intact in the zeolite cage 
system. A small additional fraction of $\mathrm{Mo}-\mathrm{Mo}_{0.7}$ at $2.15 \AA$ is observed. Apparently, the acidic environment transforms some of the precursor molecules into multiply bonded Mo-Mo species, in analogy to the formation of $\mathrm{Mo}_{2}$ compounds from $\mathrm{Mo}(\mathrm{CO})_{6}$ under acidic conditions. ${ }^{8}$ In contrast, no Mo-Mo species are detected in partially acidic zeolite $\mathrm{Y}$ or NaY hosts, and the average $\mathrm{Mo}-\mathrm{CO}$ co-ordination number remains higher.

Experiments exploring the thermal stability of the intrazeolite Ge-Mo complex demonstrate drastic changes in the EXAFS data after heating at $520 \mathrm{~K}$. At the Ge-edge, the most striking changes are cleavage of the Ge-Mo co-ordination, and an enhanced outer-shell contribution associated with backscattering from the zeolite framework metals (Figure $1 C)$. The fit for the nearest $\mathrm{Ge}$-co-ordination results in $\mathrm{Ge}-\mathrm{O}_{2.0}$ at $1.98 \AA$ and $\mathrm{Ge}-\mathrm{Cl}_{1.1}$ at $2.17 \AA$, while the zeolite framework co-ordination appears at a distance of $3.23 \AA$, typical for metals co-ordinated to zeolite 6-ring and 4-ring ion-exchange sites. The Mo-edge data of the heated samples show several convoluted shells indicating Mo-Mo species (e.g., Mo-Mo $\mathrm{Mo}_{0.7}$ at $2.20 \AA$ ) and Mo co-ordination to cationexchange sites $\left(\mathrm{Mo}-\mathrm{O}_{1.1}\right.$ at $\left.1.78 \AA\right)$. Temperature programmed desorption (TPD) MS data reveal exclusive evolution of $\mathrm{CO}$ up to $\mathrm{ca} .360 \mathrm{~K}$ and a small amount of $\mathrm{HCl}$ at higher temperatures. These observations show that the Mo and $\mathrm{Ge}$ metal fragments must be retained in the zeolite host.

We thank the Donors of the Petroleum Research Fund, administered by the American Chemical Society, for support of this research. The operational funds for NSLS beamline $\mathrm{X}-11 \mathrm{~A}$ are supported by DOE grant DE-AS0580ER10742.

Received, 10th July 1989; Com. 9/02904D

\section{References}

1 D. C. Bailey and S. H. Langer, Chem. Rev., 1981, 81, 109.

2 T. Bein, S. J. McLain, D. R. Corbin, R. D. Farlee, K. Moller, G. D. Stucky, G. Woolery, and D. Sayers, J. Am. Chem. Soc., 1988, 110, 1801.

3 L.-F. Rao, A. Fukuoka, and M. Ichikawa, J. Chem. Soc., Chem. Commun., 1988, 458.

4 N. Herron, G. D. Stucky, and C. A. Tolman, J. Chem. Soc., Chem. Commun., 1986, 20, 1521.

5 D. F. Taylor, B. E. Hanson, and M. E. Davis, Inorg. Chim. Acta, $1987,128,55$.

6 K. Moller, A. Borvornwattananont, and T. Bein, J. Phys. Chem., $1989,93,4562 ; 4205$.

7 H. Behrens, M. Moll, and E. Sixtus, Z. Naturforsch, Teil B, 1977, 32, 1105 .

8 J. L. Templeton, Prog. Inorg. Chem., 1980, 26, 211. 